\title{
Parestesi pada fraktur kompleks zigomatikomaksilaris Paresthesia in zygomaticomaxillary complex fractures
}

\author{
${ }^{1}$ Pedro Bernado, ${ }^{2,3}$ Prihartiningsih, ${ }^{3}$ Poerwati Soetji Rahajoe \\ ${ }^{1}$ Karya siswa PPDGS Ilmu Bedah Mulut dan Maksilofasial Fakultas Kedokteran Gigi Universitas Gadjah Mada \\ ${ }^{2}$ Staf pengajar PPDGS Ilmu Bedah Mulut dan Maksilofasial Fakultas Kedokteran Gigi Universitas Gadjah Mada \\ ${ }^{3}$ Staf SMF Bedah Bedah Mulut RSUP Dr. Sardjito \\ Yogyakarta, Indonesia
}

\begin{abstract}
Head trauma cases can involve os.zygoma and maxilla. Injury to the nerves is one of the complications that can be encountered as a result of the fracture fragments shift. This paper reported one case of n.infraorbitalis paresthesia following zygomaticomaxillary complex fracture. A 30 years old man was referred to the Department of Oral Surgery, Dr.Sardjito Hospital with a history of traffic accident two weeks before admission. The patient complained of right cheek area feels numbness, bite changed and there was a protrusion of bone under his right eye. Clinical examination found paresthesias of right n.infraorbitalis, left posterior open bite, and bone displace at right infraorbital rim. At the Water's $x$-ray and 3D CT scan visualized fractures involving the right maxillary and infraorbital rim. Open reduction internal fixation (ORIF) zygomaticomaxillary complex fracture, with miniplate supported by arch bar as a device to achieve individually normal occlusions, was performed under general anesthesia. Postoperative follow up indicate paresthesia symptoms gradually decreased and totally recover within 5 months. Prognosis for this case was bonam. It was concluded that ORIF with miniplate, combined with mounting arch bar can support paresthesia correction due to the displacing of fracture fragment zygomaticomaxillary complex.
\end{abstract}

Keywords: paresthesia, miniplate, arch bars, zigomaticomaxillary complex fracture, open reduction internal fixation

\begin{abstract}
ABSTRAK
Kasus trauma kepala bisa melibatkan os.zigoma dan maksila. Cedera pada saraf merupakan salah satu komplikasi yang bisa dijumpai akibat pergeseran fragmen fraktur. Pada naskah ini dilaporkan satu kasus parestesi n.infraorbitalis pada fraktur kompleks zigomatikomaksilaris. Seorang laki-laki 30 tahun dirujuk ke Bagian Bedah Mulut RSUP Dr Sardjito dengan riwayat kecelakaan lalulintas dua minggu sebelum masuk rumah sakit. Pasien mengeluh daerah pipi kanan terasa tebal, gigitan berubah dan ada tonjolan tulang di bawah mata kanan. Pemeriksaan klinis terdapat parestesi n.infraorbitalis kanan, gigitan terbuka gigi posterior kiri, dan pergeseran tulang daerah infraorbital rim kanan. Pada ronsen Water's dan CT scan 3D tampak fraktur melibatkan infraorbital rim dan maksila kanan. Dilakukan open reduction internal fixation (ORIF) fraktur kompleks zigomatikomaksilaris dengan pemasangan miniplate dan didukung dengan pemasangan arch bar sebagai alat bantu mencari oklusi, yang dilakukan dengan anestesi umum. Pasca operasi gejala parestesi berangsur-angsur berkurang, oklusi individual normal dan tonjolan tulang infraorbital rim terkoreksi. Prognosis kasus ini bonam. Disimpulkan ORIF dengan miniplate yang dikombinasi dengan pemasangan arch bar dapat mendukung terkoreksinya parestesi akibat pergeseran fragmen pada fraktur komplek zigomatikomaksilaris.
\end{abstract}

Kata kunci: parestesi, miniplate, arch bar, fraktur kompleks zigomaticomaksilaris, open reduction internal fixation

Koresponden: Pedro Bernardo, E-mail: pedrobernado.pb@gmail.com

\section{PENDAHULUAN}

Cedera yang terjadi pada daerah kepala sering terkait dengan fraktur yang melibatkan tulang-tulang wajah. ${ }^{2}$ Wajah terletak menonjol pada posisi tubuh manusia sehingga rentan mengalami cedera. Bagian prominen di regio zigomatik adalah daerah yang menahan benturan yang terberat pada cedera wajah. ${ }^{4}$

Fraktur zigomatikus merupakan fraktur yang melibatkan prosesus zigomatikus dan atau arkus zigomatikus. Garis frakturberjalan berjalan melewati sutura zigomatikofrontalis, zigomatikospenoidalis, menuju ke arah fisura orbitalis inferior, dasar orbita, daerah infraorbitalis, dinding sinus maksilaris dan kadang melibatkan arkus zigomatikus. Fraktur pada regio ini juga seringkali melibatkan orbita. Fraktur zigomatikomaksilaris merupakan fraktur zigomatik, hanya saja garis frakturnya tidak hanya melibatkan tulang zigomatik tapi juga melibatkan daerah fasial dan distal sinus maksilaris. ${ }^{8}$

Fraktur kompleks zigomatikomaksilaris adalah sekelompok fraktur yang dapat secara signifikan mempengaruhi struktur, fungsi dan tampilan wajah bagian tengah, termasuk daerah orbita. ${ }^{1}$ Hal yang menjadi perhatian adalah diperkirakan $18-83 \%$ pasien penderita fraktur kompleks zigomatikomaksilaris mengalami parestesi pada distribusi n.infraorbitalis. ${ }^{3}$ Penatalaksanaan yang optimal pada operasi fraktur kompleks zigomatikomaksilaris memerlukan adanya reduksi fragmen tulang ke posisi anatomis diikuti pemasangan fiksasi internal yang kaku.

Evaluasi, klasifikasi dan penatalaksanaancedera saraf akibat trauma maksilofasial merupakan suatu 
tantangan karena anatomi yang kompleks dan relatif jarangnya cedera saraf periferyang parah. Hal tersebut membuat ketidakpastian dalam diagnosis,klasifikasi dan penatalaksanaannya. Cedera saraf perifer relatif jarang terjadi, hal tersebutmengakibatkan ahli bedah mengadopsi pendekatan penatalaksanaan bersifat sementara dan hanya berharap terjadinya pemulihan tapi sering tanpa disertai ide yang jelas yang akan dicapai dari strateginya tersebut. ${ }^{5}$

Penatalaksaan cedera saraf perifer harus tepat untuk mengoptimalkan pemulihan fungsi sensoris dan motoris, dan mengurangi nyeri.Ahlibedah harus berpegang pada tujuan pemulihan fungsi atau penyembuhan nyeri. ${ }^{6}$ Tujuan pentalaksanaan yang segera pada cedera saraf adalahmemperoleh manfaat perbaikan saraf secara dini. Keputusan klinis harus dibuat secara terorganisasi, pertama menentukan penyebab dan letak cedera, serta mengklasifikasikan keparahan cedera. Berikutnya adalah menentukan prognosis, dan tahap akhir menentukan rencana keputusan jika dan kapan bedah diperlukan. ${ }^{5}$

Mekanisme terjadinya cedera saraf pada trauma maksilofasial, yaitu tekanan atau compression, regangan atau stretch, dan pembelahan atau division. Tekanan adalah mekanisme cedera saraf perifer yang paling mungkin terjadi pada trauma maksilofasial. Tingkatan cedera terkait dengan besar gaya yang mengenai saraf, lamanya gaya bekerja, jumlah dan ukuran fasicles, serta jumlah jaringan ikat. Cedera karena regangan terkait dengan pergeseran fraktur di sekitar saraf intraoseus dan trauma tumpul pada saraf ekstraoseus yang juga menyebabkan deformitas parah pada jaringan lunak. Cabang-cabang saraf ekstraoseus memiliki risiko terkena cedera besar karena laserasi hingga terputus atau terbelah.Cedera terbuka jaringan lunak wajah dapat menyebabkan terputusnya saraf di daerah yang terlibat. ${ }^{5}$

Saraf intraoseus terlindungi oleh tulang yang mengelilinginya, tetapi rentan mengalami cedera regangan jika tulang tersebut fraktur dan bergeser. Saraf ekstraoseus berisiko cedera pada luka terbuka dan cedera tumpul yang meluas. ${ }^{5}$ Seperti terlihat pada tabel 1, cedera saraf dapat diklasifikasikan menurut tingkat defisit fungsionalnya,yaitu anestesia atau paralisis, parestesia dan disestesia. Informasi ini dipadukan dengan pengetahuan akan cedera jaringan saraf dan skeletal serta mekanisme cedera akan mengarahkan ahlibedah menentukan klasifikasi awal anatomi patologis cedera saraf.

Kondisi saraf diklasifikasikan menjadi utuh, terpotong, tertekan atau teregang. Hal tersebut dapat dinilai dengan inspeksi pada luka terbuka; pada luka tertutup kondisi saraf tidak diketahui secara pasti. Pemeriksaan klinis, pengetahuan mekanisme trauma dankondisiluka merupakan hal penting menentukan kondisi apa yang mungkin terjadi pada saraf. ${ }^{5}$

Percabangan n.trigeminus yang paling sering mengalamicedera pada trauma maksilofasial adalah cedera n.infraorbitalis saat terjadi fraktur zigomatikoorbita dan cedera n.alveolaris inferior pada fraktur korpus dan angulus mandibula. Secara singkat pemeriksaan sensoris $n$. trigeminus dilakukan pada pasien trauma. Light touch dan pinprick nociception merupakan tes minimal yang dapat dilakukan untuk mengklasifikasi (tabel2) dan menentukan keparahan dan perluasan cedera. Light touch mudah dilakukan dengan aplikasi cotton tipped.Pemeriksaan nosiseptif dilakukan dengan objek yang tajam, seperti pin, jarum atau pinset pada daerah distribusi saraf yang cedera. $^{5}$

Tabel 1 Klasifikasi cedera saraf sesuai tingkat defisit fungsional. ${ }^{5}$

\begin{tabular}{ccc}
\hline Jenis Cedera & \multicolumn{1}{c}{ Keadaan } \\
\hline Anestesia & $\begin{array}{l}\text { Kondisi cedera saraf yang terkait benturan yang hebat, regangan, atau cedera yang memutus saraf. Ahli } \\
\text { bedah harus memperkirakan kemungkinan terpotongnya saraf secara menyeluruh. Prognosis untuk } \\
\text { pemulihan spontan adalah kurang baik dan tergantung lokasi cedera saraf. }\end{array}$ \\
\hline Parestesia & $\begin{array}{l}\text { Saraf yang parestesia pada pemeriksaan klinis jaringan lunak dapat sebagian besar masih utuh. Ahli } \\
\text { bedah harus menilai jaringan lunak dan skeletal untuk memastikan tidak adanya hambatan untuk } \\
\text { pemulihan cedera saraf. Prognosis untuk keadaan ini paling baik untuk adanya pemulihan spontan. }\end{array}$ \\
\hline \multicolumn{5}{c}{ Tampak lebih sering kemudian pada periode pasca cedera atau pasca operasi, dan paling sering terjadi } \\
pada pasien trauma akut. Disestesia dapat tampak dari keluhan subjektif pasien berupa nyeri pada \\
distribusi anatomis saraf yang cedera, dengan bukti klinis adanya rasa dan persepsi nyeri pada pemberian \\
perangsangan yang bersifat tidak nyeri.
\end{tabular}


Tujuan penatalaksanaan awal fraktur adalah memutuskan perlu-tidaknya tindakan bedah secara dini atau akan dilakukan observasi untukpemulihan. Tipe, mekanisme, keparahan dan lokasi cedera harus dinilai dan menjadi faktor pengambilan keputusan. ${ }^{5}$

Penatalaksanaan cedera saraf dengan gangguan berupa parestesi akibat tekanan singkat dilakukan dengan memonitor pemulihan (tabel 3), sementara tindakan bedah jarang diperlukan karena biasanya masuk dalam cedera sedang (Sunderland tipe I atau II). Penatalaksaan parestesi akibat tekanan yang bersifat konstan berupa mengidentifikasi sumber tekanan dengan mengeksplorasi dan menghilangkan sumber kompresi, kemudian melindungi saraf dari kompresi yang berasal dari jaringan parut, tindakan bedah mungkin diperlukan (Sunderland tipe I, II atau III). Penatalaksaan parestesi akibat regangan yang singkat berupa memonitor pemulihan,tindakan bedah jarang diperlukan, biasanya merupakancedera ringan (Sunderland tipe I atau II). Penatalaksanaan parestesi akibat regangan yang menetap berupa pemeriksaan sensoris tingkat dasar, menghilangkan regangan, menghilangkan tekanan, melindungi saraf dari tekanan berulang. Penatalaksanaan parestesi akibat cedera akut, jarang diperlukan intervensi bedah yang segera, tindakan bedah yang dilakukan biasanya hanya bertujuan menghilangkan tekanan, sementara pemotongan dan perbaikan luka jarang diindikasikan. $^{5}$

Pembahasan artikel ini dimaksudkan untuk melaporkan penanganankasus parestesi pada fraktur kompleks zigomatikomaksilaris pasca kecelakaan lalulintas

\section{KASUS}

Seorang laki-laki 30 tahun dirujuk ke Bagian Bedah Mulut RSUP Dr Sardjito dengan riwayat kecelakaan lalulintas tepat dua minggu sebelumnya. Pasien mengeluh daerah pipi kanan terasa tebal, gigitan berubah dan ada tonjolan tulang di bawah mata kanan; keadaan umum pasien baik, dan tandatanda vital dalam batas normal. Pada pemeriksaan ekstraoral tampak wajah yang asimetris pada regio infraorbitalis dextra karena ada sedikit benjolan. Pemeriksaan intraoral menunjukkan adanya gigitan terbuka pada sisi kanan regio 16, 17, dan 18. Dari pemeriksaan klinis menunjukkan terdapat parestesi n.infraorbitalis dextra. Pemeriksaan darah lengkap menunjukkan hemostasis dan elektrolit dalam batas normal; pada foto ronsen dada kesan jantung dan paru-paru dalam batas normal.Pemeriksaan radiografi ronsen panoramik (gambar 1A), Water's (gambar 1B), dan 3D CT (gambar 2) menampakkan fraktur melibatkan infraorbital rim dan maksila dextra. Hasil CT scan kepala ditemukan edema cerebri, deviasi septum nasi dan hematosinus.

Berdasarkan data klinis dan radiografi, kelainan penderita ini didiagnosis sebagai fraktur kompleks zigomatikomaksilaris disertai komplikasi parestesi n.infraorbitalis dextra. Penatalaksanaannya meliputi tahap preoperasi berupa konsultasi ke Bagian Saraf untuk penatalaksanaan edema cerebri dan konsultasi Bagian Telinga Hidung Tenggorokan untuk kondisi deformitas septum nasi dan hematosinus. Dilakukan pemasangan interdental wiring dengan arch bar di gigi rahang atas dan bawah yang dilakukan dengan anestesi lokal. Durante operasi dilakukan prosedur

Tabel 3 Klasifikasi patofisiologi dan prediksi penyembuhan. ${ }^{7}$

\begin{tabular}{ccc}
\hline Tipe cedera & Jenis penyembuhan & Lama penyembuhan \\
\hline Neupraksia & Remielinasi dari segmen yang terlibat & $2-12$ minggu \\
Limited axonal loss & Pertumbuhan kolateral akson yang masih bertahan & $2-6$ bulan \\
Intermediate axonal loss & Pertumbuhan kolateral dan regenerasi akson dari lokasi cedera & $2-6$ bulan \\
Severe axonal loss & Regenerasi akson & $2-18$ bulan \\
Terputusnya saraf secara total & Tidak ada penyembuhan tanpa adanya graft saraf & $2-18$ bulan \\
\hline
\end{tabular}

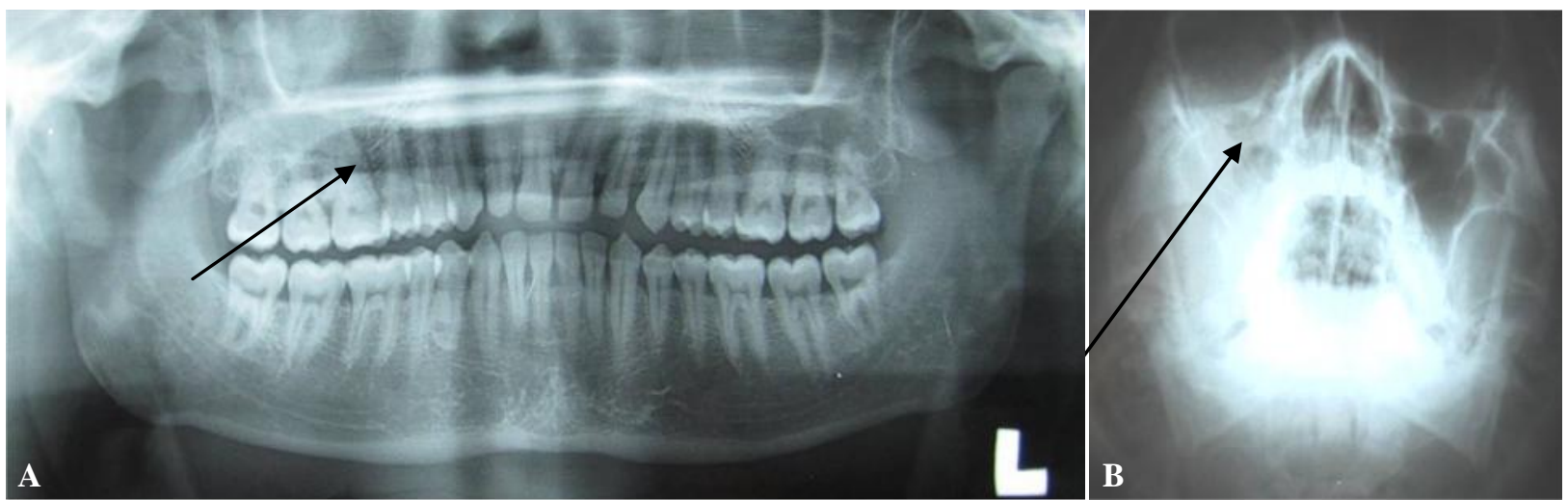

Gambar 1A Ronsen panoramik, B ronsen Water's 
open reduction internal fixation (ORIF) pada garis fraktur infraorbita rim. Operasi diawali dengan insisi di infraorbita untuk memperoleh akses ke garis fraktur infraorbita rim, inspeksi ke daerah n.infraorbitalis dextra, reposisi fragmen fraktur infraorbita rim lalu fiksasi dengan miniplate $2 \mathrm{~mm}$ dan penutupan luka insisi. Prosedur ORIF pada fraktur maksila dimulai dengan insisi marginal intra oral dari regio 12 hingga 17 , reposisi fragmen fraktur diikuti dengan fiksasi menggunakan miniplate $2 \mathrm{~mm}$ dan penutupan luka insisi. Medikasi iv pascaoperasi diberikan antibiotik, anti-inflamasi,hemostatik dan analgetik.Pasien rawat inap selama tiga hari pasca operasi, dilanjutkan dengan rawat jalan (Tabel 4).
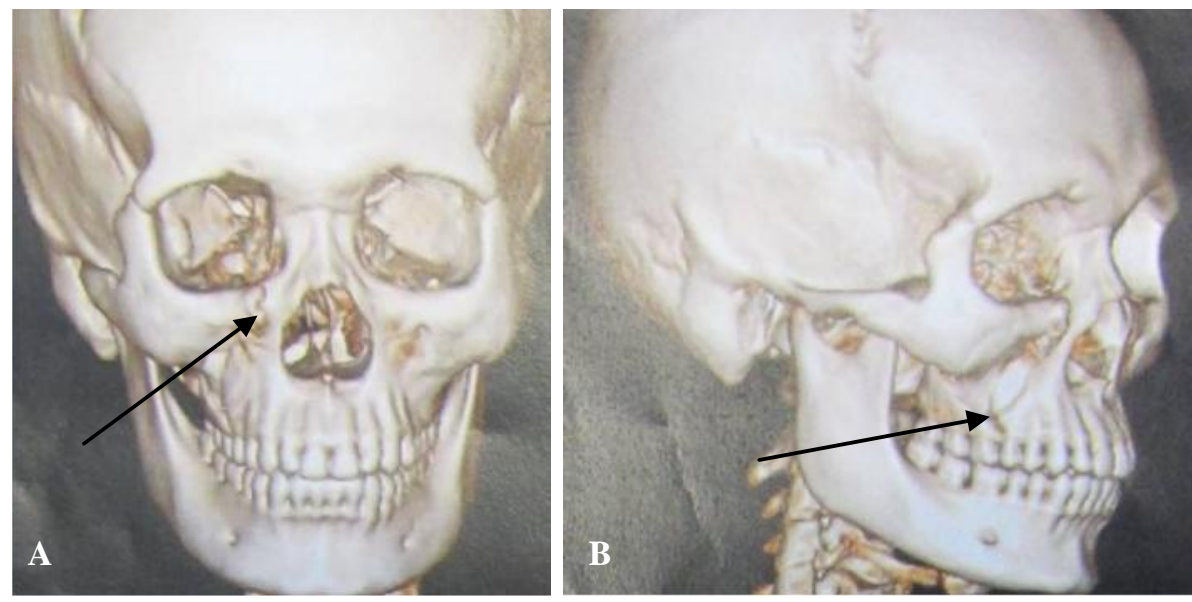

Gambar 2 Gambaran foto ronsen 3D CT; A aspek anterior, dan B aspek lateral kanan.

Tabel 4 Kontrol pasca operasi

\begin{tabular}{|c|c|c|}
\hline Pasca operasi & Pemeriksaan Subjektif & Pemeriksaan Objektif dan Tindakan \\
\hline Hari k & $\begin{array}{l}\text { Pipi \& kelopak mata bawah kanan rasa } \\
\text { tebal, buka mulut terbatas sebab nyeri } \\
\text { jika digerakkan, perdarahan sudah tidak } \\
\text { terasa, gigitan RA \& RB belum nyaman. }\end{array}$ & $\begin{array}{l}\text { KU sedang, VS: d.b.n., edema pipi }(+) \text {, hematom infraorbita } \\
(+) \text {, trismus }(+) \text {, perdarahan }(-) \text {, mual }(-) \text {, muntah }(-) \text {, demam }(-) \text {, } \\
\text { parestesi n.infraorbitalis dextra }(+) \text {. Tindakan: pemasangaan } \\
\text { IMW karet. Obat iv dilanjutkan kecuali obat hemostasis. }\end{array}$ \\
\hline Hari ke-2 & $\begin{array}{l}\text { Rasa tebal di pipi \& kelopak mata } \\
\text { bawah kanan, nyeri berkurang,sudah } \\
\text { tidak terasa perdarahan, gigitan RA \& } \\
\text { RB lebih nyaman dengan IMW. }\end{array}$ & $\begin{array}{l}\text { KU baik, VS: d.b.n, edema pipi }(+) \text {, hematom infraorbita }(+) \text {, } \\
\text { perdarahan }(-) \text {, parestesi n.infraorbitalis dextra }(+) \text {. Tindakan: } \\
\text { pemasangaan IMW kawat } 0,3 \text {. Obat iv dilanjutkan. }\end{array}$ \\
\hline Hari & $\begin{array}{l}\text { Pipi \& kelopak mata bawah kanan rasa } \\
\text { tebal, daerah pipi kanan terasa tebal, } \\
\text { tidak nyeri. Perut tidak terasa perih. }\end{array}$ & $\begin{array}{l}\text { KU baik, VS: d.b.n., edema pipi (+), hematom infraorbita }(+) \text {, } \\
\text { perdarahan }(-) \text {, parestesi n.infraorbitalis kanan }(+) \text {. Tindakan: } \\
\text { rawat jalan \& medikasi antibiotik, anti-inflamasi, analgetik } \\
\text { dan ruboransia Meticobal } 1500 \mathrm{mcg} / \text { hari. }\end{array}$ \\
\hline Hari & $\begin{array}{l}\text { Pipi kanan rasa tebal,ikatan RA \& RB } \\
\text { sedikit longgar. Tidak ada nyeri, } \\
\text { demam, mual. Perut tidak terasa perih. }\end{array}$ & $\begin{array}{l}\text { KU baik, VS: d.b.n., edema pipi (+), hematom infraorbita (+), } \\
\text { parestesi n.infraorbitalis dextra (+). Tindakan: kencangkan } \\
\text { IDW \& IMW, lepas jahitan ekstraoral \& intraoral. Ruboransia: } \\
\text { Meticobal } 1500 \text { mcg/hari untuk } 2 \text { minggu. }\end{array}$ \\
\hline Ming & $\begin{array}{l}\text { Terasa tebal di pipi kanan, ikatan RA } \\
\text { \& RB sedikit longgar. Tidak ada } \\
\text { nyeri, demam, mual. }\end{array}$ & $\begin{array}{l}\text { KU baik, VS: d.b.n, edema pipi berkurang, hematom infraorbita } \\
\text { me(-), tindakan: lepas IDW \& IMW, jaga OH \& edukasi diet } \\
\text { lunak. Pemeriksaan sensoris: parestesi n.infraorbitalis dextra } \\
\text { (+). Ruboransia: Meticobal } 1500 \mathrm{mcg} / \text { hari untuk } 2 \text { minggu. }\end{array}$ \\
\hline Ming & Teras & $\begin{array}{l}\text { KU baik, VS: d.b.n., edema pipi (-), hemator } \\
\text { pemeriksaan sensoris: parestesi n.infraorbit } \\
\text { Ruboransia: Meticobal } 1500 \mathrm{mcg} / \text { hari untuk } 4\end{array}$ \\
\hline Minggu ke-8 & Rasa tebal di pipi kanan berkurang & $\begin{array}{l}\text { KU baik, VS: d.b.n., edema pipi (-), hematom infraorbita (-), } \\
\text { pemeriksaan sensoris: parestesi n.infraorbitalis dextra (+). } \\
\text { Tindakan: Kontrol. }\end{array}$ \\
\hline Bulan ke-3 & rkurang & $\begin{array}{l}\text { KU baik, VS: d.b.n., edema pipi (-), hematom infraorbita (-), } \\
\text { pemeriksaan sensoris: parestesi n.infraorbitalis dextra (+). } \\
\text { Tindakan: kontrol. }\end{array}$ \\
\hline Bulan ke-5 & Tidak terasa tebal di pipi kanan & $\begin{array}{l}\text { KU baik, VS: d.b.n., edema pipi (-), hematom infraorbita (-), tes } \\
\text { sensoris: parestesi n.infraorbitalis dextra (-).Tindakan: kontrol. }\end{array}$ \\
\hline
\end{tabular}

$\mathrm{KU}$ : Kondisi umum, VS: vital sign, IDW: interdental wiring, IMW: intermaxillary wiring. 


\section{PEMBAHASAN}

Kasus ini melaporkan fraktur yang melibatkan zigomatikomaksilaris, tepatnya di regio infraorbita rim dextra dan maksila dextra. Kasus fraktur zigoma biasa terjadi pada empat persendian, yaitu infraorbita rim, zigomatikomaksilaris, zigomatiokofrontalis dan arkus zigomatikus. ${ }^{10}$ Pada kasus ini persendian yang terlibat adalah regio infraorbita rim yaitu pergeseran fraktur yang tampak secara klinis pada palpasi dan terkonfirmasi dengan pemeriksaan ronsen Water's, ${ }^{9}$ CT aksial dan 3D CT.

Penatalaksanaan fraktur zigomatikomaksilaris kompleks terutama terkait reduksi fragmen tulang. ${ }^{9}$ Jenis pendekatan bedah sesuai dengan besarnya pergeseran ${ }^{9}$ dan lokasi fraktur. ${ }^{10}$ Pada kasus ini, teknik reduksi fraktur dilakukan dengan ORIF sesuai indikasi penatalaksanaan kasus fraktur zigoma yang melibatkan fraktur pada regio infraorbita rim, yaitu dengan open reduction. ${ }^{5}$ Teknik ORIF dilakukan dengan adekuat sehingga pasca operasi tonjolan di regio orbita rim bisa terkoreksi. Jika reduksi tidak akurat maka hanya sedikit posisi mengunci antara fragmen tulang sehingga membuat fragmen tulang tidak stabil. Pada kasus fraktur regio infraorbita diperlukan fiksasi mekanis yang adekuat sehingga mengurangi risiko pergeseran ulang. ${ }^{10}$ Pada kasus ini digunakan miniplate 2 mmuntuk memperoleh fiksasi mekanis sehingga menahan fragmen tulang sesuai posisi anatomis yang diharapkan. Saat preoperasi, pasien sudah dipasangi arch bar di rahang atas dan bawah kemudian saat satu hari pasca operasi pasien dipasang intermaxillary wiring (IMW) karet elastik untuk mendapatkan oklusi yang adekuat. Pada hari kedua pascaoperasi, IMW dipertahankan dengan kawat 0,3 selama dua minggu untuk memberikan periode fiksasi dan imobilisasi yang adekuat. Saat kontrol dua minggu pascaoperasi,open bite posterior kanan terkoreksi dan diperoleh oklusi individual yang baik.

Fraktur terisolasi di dasar orbita,infraorbita rim dan dinding anterior sinus maksilaris menunjukkan manifestasi klinis berupa parestesi atau anestesi. ${ }^{9}$ Menurut klasifikasi cedera saraf perifer,berdasarkan tingkat defisit fungsionalnya kasus ini merupakan parestesi.

Parestesi padakasus ini melibatkan tulang regio infraorbitarim dan maksila. Penatalaksanaan pertama parestesi cedera saraf perifer yang perlu diperhatikan dalam kasus ini adalah penyebab cederanya, yaitu adanya trauma wajah pasca kecelakaan lalulintas. Letak cedera di daerah pipi kanan tampak sebagai cedera skeletal meluas daerah infraorbita melibatkan tulang maksila kanan dan infraorbital rim. Durante operasi dilakukan insisi di regio infraorbita sehingga menampakkan garis fraktur dan pada eksplorasi ke arah inferior tampakbundeln.infraorbitalis yangutuh. Mekanisme cedera saraf mungkin karena adanya regangan akibat pergeseran fragmen fraktur sehingga terjadi trauma pada saraf yang terletak di dalam tulang. Selain itu dimungkinkan pula karena adanya kompresi akibat trauma tumpul pada saraf tersebut saat keluar dari foramen infraorbita.

Kasus ini menunjukkan kemungkinan telah terjadi cedera saraf aksonotmesis sesuai klasifikasi Seddon dan masuk cedera saraf tipe 2, tipe 3 atau tipe 4 menurut klasifikasi Sunderland, yaitu keadaan degenerasi akson dengan kondisi endoneurium atau perineurium mengalami derajat kerusakan tertentu. Saraf intraoseus akan dilindungi oleh tulang yang mengelilinginya, tetapi rentan mengalami cedera regangan jika tulang tersebut fraktur dan bergeser serta berisiko terjadi sindroma kompartemen karena saraf berkedudukan di dalam ruang yang tidak dapat bertambah luas sehingga intoleran dengan adanya edema. Perineurial edema dapat menekan fasikuler sehingga muncul defisit neurologis. ${ }^{5}$

Cedera saraf tepi karena adanyaregangan lebih bermasalah dibanding cedera akibat tekanan karena jaringan saraf yang cedera biasanya lebih luas dan keparahan cedera tidak dapat ditentukan secara akurat dengan inspeksi. Epineurium mungkin akan tampak utuh dan normal tapi mungkin ada kerusakan fasikuler yang bermakna. Nervus infraorbitalis rentan mengalami cedera karena melekat pada foramennya, serta akibat terjepit mandibula dan maksila akibat gaya tekanan dari trauma tumpul.

Prognosis terjadinya penyembuhan spontan pada kasus ini adalah baik, dengan perkiraan pemulihan defisit neurologis berlangsung selama 2-6 bulan. ${ }^{5,7}$ Tindakan bedah berupa reposisi fragmen fraktur ke posisi anatomis membantu menghilangkan tekanan pada n.infraorbitalis.Parestesi pada distribusi nervus infraorbita seringkali masih terjadi pasca operasi untuk beberapa waktu. Reposisi dari fragmen tulang hingga tidak ada lagi jepitan pada n.infraorbitalis meningkatkan pemulihannya. ${ }^{9}$ Defisit neurologis mengalami pemulihan secara total pada bulan kelima pascaoperasi.

Pascaperawatan, disimpulkan bahwa pemasangan ORIF dengan miniplate yang dikombinasi dengan pemasangan arch bar dapat mendukung pemulihan parestesi akibat pergeseran fragmen pada fraktur kompleks zigomatikomaksilaris. Meskipun demikian, keputusan klinis penatalaksanaancedera saraf perifer harus dibuat secara terorganisasi dengan langkah awal menentukan penyebab dan letak cedera, serta klasifikasi keparahan cedera. Tahap berikut adalah menentukan prognosis; dan tahap akhir menentukan 
rencana penatalaksanaan. Pemeriksaan awal secara akurat disarankan untuk mengumpulkan informasi mengenai jenis, mekanisme, keparahan dan lokasi cedera,karenahal tersebut menjadi faktor acuan untuk pengambilan keputusan untuk penatalaksanaan yang adekuat.

\section{DAFTAR PUSTAKA}

1. Lee EI, Mohan K, Koshy JC, Hollier LH. Optimizing the surgical management of zygomaticomaxillary complex fractures. Thieme Medical Publishers. Seminars in Plastic Surgery 2010; 24(4): 389-97

2. Young CC, editor. Facial fractures. Mescape Reference, WebMD LLC, 2011 Sep, (Cited 2012 Des 1). Available from: URL: http://emedicine.medscape.com/article/84613-overview

3. Chang CM, Ko EC, Kao CC, Chang PY, Chen MYC. Incidence and clinical significance of zygomaticomaxillary complex fracture involving the temporomandibular joint with emphasis on trismus. Kaohsiung J Med Sci 2012; 20: $1-5$

4. Rana M, Warraich R, Tahir S, Iqbal A, von See C, Eckardt AM, et al. Surgical treatment of zygomatic bone fracture using two points fixation versus three point fixation-a randomised prospective clinical trial. Trials 2012; 13: 36

5. Labanc JP. Maxillofacial nerve injuries: evaluation, classification, and management. In: Fonsesca RJ, Walker RV, Betts NJ, Barber HD, editors. Oral and maxillofacial trauma, vol.2. $2^{\text {nd }}$ Ed. Philadelphia: WB Saunders Company; 1997. p. 913-24.

6. Myckatyn TM, Macjinnon SE. Microsurgical repair of peripheral nerves and nerve grafts. In: Thorne $\mathrm{CH}$, Beasly RW, Aston SJ, Bartlett SP, Gurtner GC, Spear SL, editors. Grabb and Smith's plastic surgery. $6^{\text {th }}$ Ed. Philadelphia: Lippincott Williams and Wilkins; 2007. p.73-6.

7. Quan D, Bird SJ. Nerve conductions studies and electromyography in the evaluation of peripheral nerve injuries. The University of Pennsylvania Orthopaed J 1999; 12: 45-51.

8. Budihardja AS, Masykur R. Fraktur wajah. Dalam: Juwono L, editor. Trauma oral dan maksilofasial. Jakarta: Penerbit Buku Kedokteran EGC; 2012. p.144-152,165.

9. Gerlock AM, Sinn DP. Anatomic, clinical, surgical, and radiologic correlation of the zygomatico complex fracture. Am J Roentgenol 1977; 128: 238.

10. Kim OY. Transcutaneus reduction and external fixation for the treatment of noncomminuted zygoma fracture. J Oral Maxillofac Surg 1998; 56: 1382,1384-6. 